\title{
A tiny bleb at Junctional Dilatation of the Posterior Communicating Artery as a Predisposing Factor for Development of a De Novo Aneurysm
}

\author{
Kuhyun Yang, MD', Wonhyoung Park, MD', , Hae-Won Koo, MD', Dae Chul Suh, MD, PhD'
}

Formation of de novo aneurysm from a junctional dilatation at the origin site of the posterior communicating artery (PcomA) has been rarely reported. In this case report, three females in sixth decades of age developed a de novo aneurysm from the junctional dilatation of the PComA with a tiny bleb-like lesion over 5 years after initial presentation.

Key Words: Junctional dilatation; Aneurysm; Posterior communicating artery

Diffuse dilatation at the origin site of the posterior communicating artery (PcomA) is known as a "junctional dilatation" or an "infundibulum". Usually, the PcomA is originated from the apex of the junctional dilatation and it has a triangular shape $[1,2]$. The incidence has been reported to be up to $17 \%$ of catheter angiography [3]. There was no proven histological abnormalities in an autopsy study of junctional dilatation at the PcomA [4]. Epstein et al. reported that seven junctional dilatations at the origin of the PcomA from routine autopsy revealed that adventitia, media, internal

'Department of Radiology, Asan Medical Center, Ulsan University School of Medicine, Seoul, Korea

${ }^{2}$ Department of Neurosurgery, Asan Medical Center, Ulsan University School of Medicine, Seoul, Korea

Received February 18, 2016;

accepted after revision February 24, 2016.

Correspondence to: Dae Chul Suh, MD, PhD, Department of Radiology, University of Ulsan, College of Medicine, Asan Medical Center, 88, Olympic-ro 43-gil, Songpa-gu, Seoul 138-736, Korea.

Tel. 82.2.3010.4366 Fax. 82.2.476.0090

E-mail: dcsuh@amc.seoul.kr

This is an Open Access article distributed under the terms of the Creative Commons Attribution Non-Commercial License (http://creativecommons.org/licenses/by-nc/3.0) which permits unrestricted non-commercial use, distribution, and reproduction in any medium, provided the original work is properly cited. elastic membrane, and intima were intact. They concluded that the junctional dilatation at the PcomA was a normal variation and not a site having predilection to bleeding or future true aneurysmal dilatation.

Although the junctional dilatation at the PcomA is mostly considered to be a benign variant, several reports have documented the evolution of such a dilatation to a saccular de novo aneurysm with subsequent bleeding especially at the PcomA $[5,6]$. Therefore, the management and follow-up of an incidentally diagnosed junctional dilatation at the PcomA remains uncertain whether there is no possibility to develop aneurysm at all or not. We presented three patients who showed transformation from junctional dilatations at the PcomA to a saccular aneurysm and report characteristic finding on 3D angiography which has not been described previously.

\section{CASE SERIES}

Summary of three patients was shown in Table 1. Detailed angiographic findings were compared in Table 2.

\section{Case I}

A 53-year-old healthy female patient developed an 


\section{Kuhyun Yang, et al.}

acute onset of severe occipital headache. Computed tomography (CT) scans showed a subarachnoid hemorrhage $(\mathrm{SAH})$ mainly around the brainstem. Cerebral angiography revealed a saccular aneurysm with a maximum diameter of $4 \mathrm{~mm}$ in the right superior cerebellar artery origin and junctional dilata- tion at both PcomA origins. 3D rotational angiography showed that bilobulated bleb in the left junctional dilatation (Fig. 1A). The right SCA aneurysm was then treated by clipping surgery. One-year follow-up CT angiogrphy showed that complete occlusion of right SCA aneurysm and no change of both side junctional

Table 1. Summary of Three Patients with De Novo Aneurysm Developing from Junctional Dilatation

\begin{tabular}{cccccc}
\hline $\begin{array}{c}\text { Patient } \\
\text { number }\end{array}$ & $\begin{array}{c}\text { Age/ } \\
\text { Sex }\end{array}$ & $\begin{array}{c}\text { SAH } \\
\text { (Coexisting ruptured aneurysm) }\end{array}$ & $\begin{array}{c}\text { Presence } \\
\text { of HT }\end{array}$ & $\begin{array}{c}\text { Time interval of } \\
\text { aneurysm detection }\end{array}$ & $\begin{array}{c}\text { Management of } \\
\text { de novo aneurysm }\end{array}$ \\
\hline 1 & $53 / F$ & $+($ Rt. SCA $)$ & + & 63 months & Clipping surgery \\
2 & $57 / F$ & $+($ Lt. MCA and Lt. AchoA) & + & 61 months & Observation \\
3 & $55 / F$ & $+($ Lt. MCA) & + & 62 months & Clipping surgery \\
\hline
\end{tabular}

An., aneurysm; SAH, subarachnoid hemorrhage; Rt., right; Lt., left; SCA, superior cerebellar artery; MCA, middle cerebral artery; AchoA, anterior choroidal artery; PcomA, posterior communicating artery; JD, junctional dilatation; HT, hypertension; Tx, treatment

Table 2. The Comparison Between Bilateral Junctional Dilatations in Each Individual Case

\begin{tabular}{cccccc}
\hline $\begin{array}{c}\text { Patient } \\
\text { number }\end{array}$ & $\begin{array}{c}\text { Side of } \\
\text { JD }\end{array}$ & $\begin{array}{c}\text { PCA filling from PcomA } \\
\text { on ICA angiogram }\end{array}$ & $\begin{array}{c}\text { *Size of } \\
\text { PcomA }(\mathrm{mm})\end{array}$ & $\begin{array}{c}\text { Presence of } \\
\text { bleb }\end{array}$ & $\begin{array}{c}\text { De novo } \\
\text { aneurysm }\end{array}$ \\
\hline 1 & Rt. ICA & Full filling & 0.86 & No & Yo \\
Lt. ICA & Full filling \& more prominent & 1.33 & No & No \\
2 & Rt. ICA & No filling & 0.46 & Yes & Yes \\
& Lt. ICA & Full filling (Fetal type) & 1.96 & No & Yes \\
\hline
\end{tabular}

JD, junctional dilatation; Rt., right; Lt., left; ICA, internal carotid artery; PCA, posterior cerebral artery; PcomA, posterior communicating artery. *The size of PcomA was measured at the most tangential view.
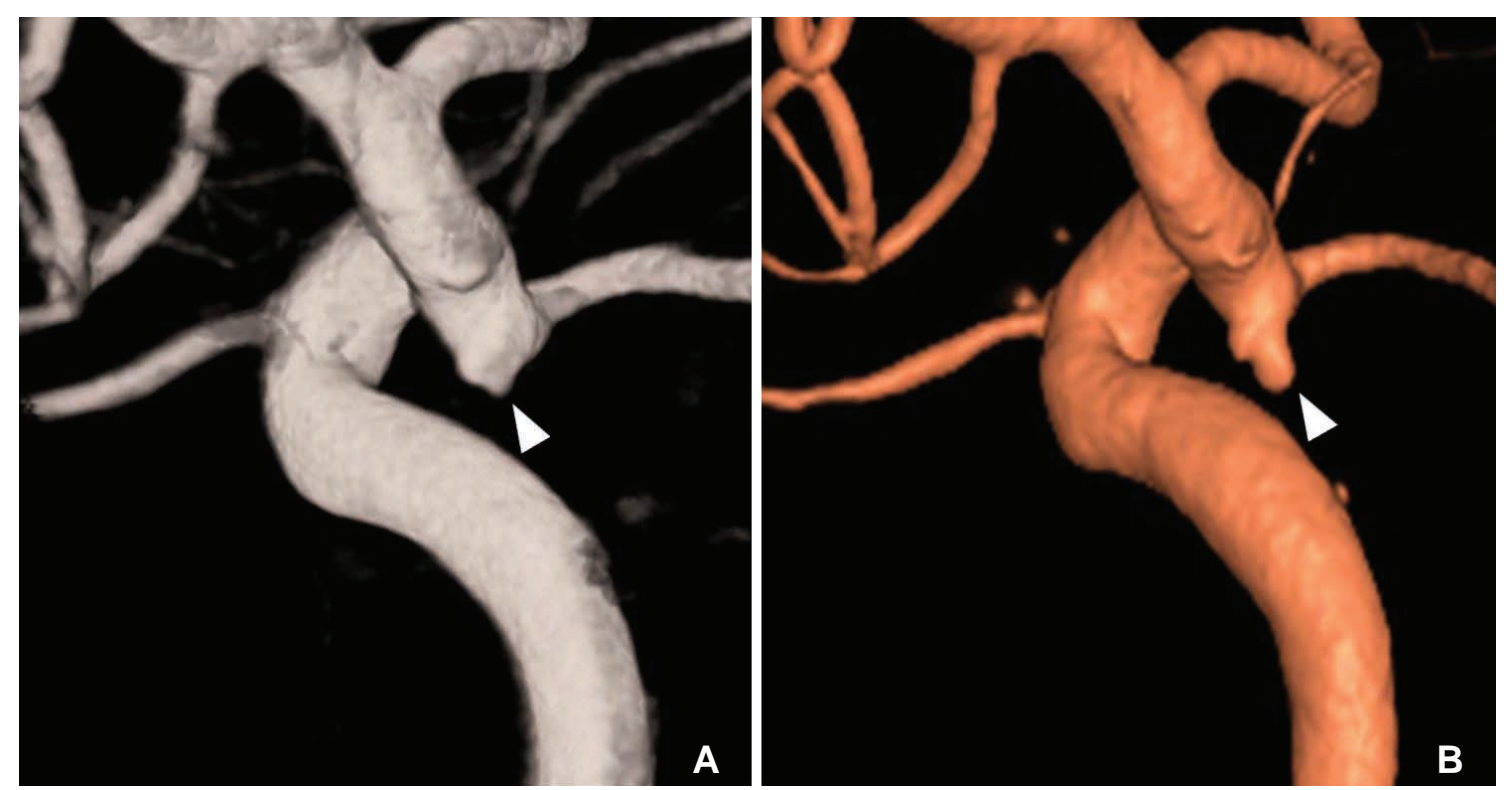

Fig. 1. A 53-year-old female (Case 1). (A) Initial 3-D rotational angiogram shows a bilobulated bleb (arrowhead) at junctional dilatation of the posterior communicating artery (PcomA). (B) Follow-up 3-D rotational angiogram obtained 5 years later shows de novo aneurysm formation at the site of the previous bleb (arrowhead). 


\section{De Novo Aneurysm at Junctional Dilatation of PComA}

dilatations at the PcomA origin. Five-year follow-up angiography revealed a de novo internal carotid artery (ICA) aneurysm developing from a junctional dilatation at the origin of the left PcomA (Fig. 1B). Considering the direction, shape and position of the bleb, demonstration of a bleb by 3-D rotational angiography at the dominant side of bilateral junctional dilatation of the P-comA seems to be an important risk factor for evolution of a newly developed aneurysm. The patient underwent another clipping surgery for this de novo aneurysm.

\section{Case II}

A 57-year-old healthy female presented with an acute onset of altered mentality. CT showed a SAH mainly noted around the left Sylvian fissure and cerebral angiography revealed a bilobulated aneurysm with a maximum diameter of $4 \mathrm{~mm}$ in the left MCA bifurcation and a round saccular aneurysm with a maximum diameter of $5 \mathrm{~mm}$ in the left anterior choroidal artery origin. In addition, there was a triangular junctional dilatation at the origin of the PcomA in both sides. The left sided PcomA origin with junctional dilatation possessed a tiny bleb (Fig. 2A). Both aneurysms at the left MCA and the left anterior choroidal artery were clipped on single stage. One-year follow-up CT angiography showed complete occlusions of the clipped aneurysms at the left MCA and the left anterior choroidal artery, and no change of junctional dilatations at both sides of the PcomA origin. Five-year follow-up
$3 \mathrm{D}$ rotational angiography revealed a de novo aneurysm formation at a previous junctional dilatation at the origin of the left PcomA (Fig. 2B).

\section{Case III}

A 55-year-old healthy female patient presented with an acute onset of seizure like movement. CT angiography showed a SAH with the maximum around the left Sylvian fissure and revealed a saccular aneurysm with a maximum diameter of $8 \mathrm{~mm}$ in left MCA bifurcation origin. The left MCA aneurysm was treated by clipping. CT angiography also revealed a triangular junctional dilatation at the origin of both PcomA. 3D rotational angiography showed that the left sided junctional dilatation possessed a tiny bleb (Fig. 3A). One-year follow-up CT angiography showed complete occlusions of the left MCA aneurysm and no change of junctional dilatations at both sides of the PcomA origin. Five-year follow-up 3D rotational angiography revealed a de novo aneurysm formation developing from junctional dilatation at the origin of the left PcomA (Fig. 3B). The aneurysm was clipped.

\section{DISCUSSION}

Our study showed development of de novo aneurysm from junctional dilatation of the PcomA origin in three patients who had been followed for about 5 years after initial presentation. The initial 3D rotational angiography at the time of diagnosis showed a tiny bleb at the
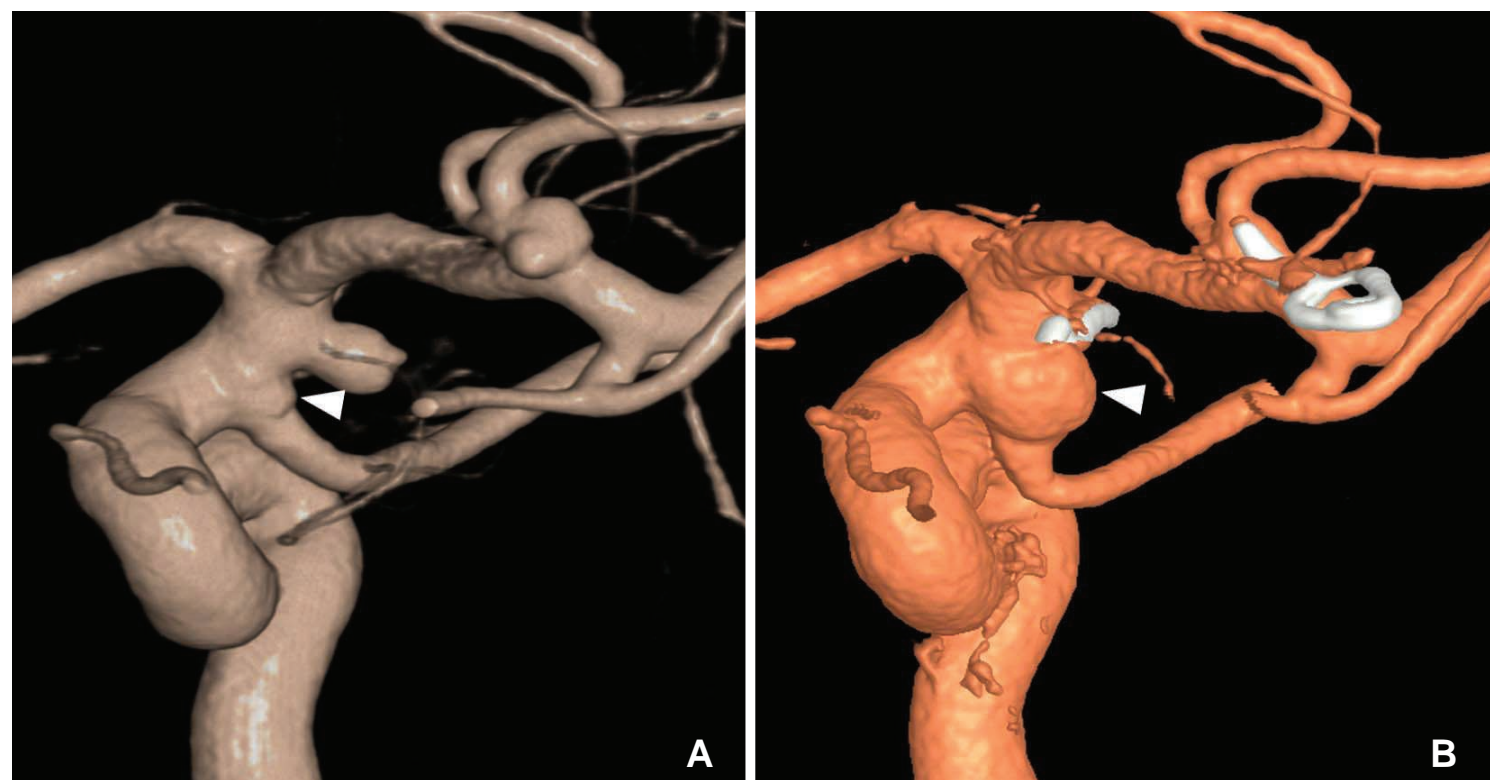

Fig. 2. A 57-year-old female (Case 2). (A) Initial angiogram showed a tiny bleb (arrowhead) at triangular junctional dilatation of the PcomA. (B) Follow-up angiogram obtained five years later revealed a de novo aneurysm formation from a junctional dilatation at the PcomA. It located just below the clipping site of the anterior choroidal artery aneurysm. 

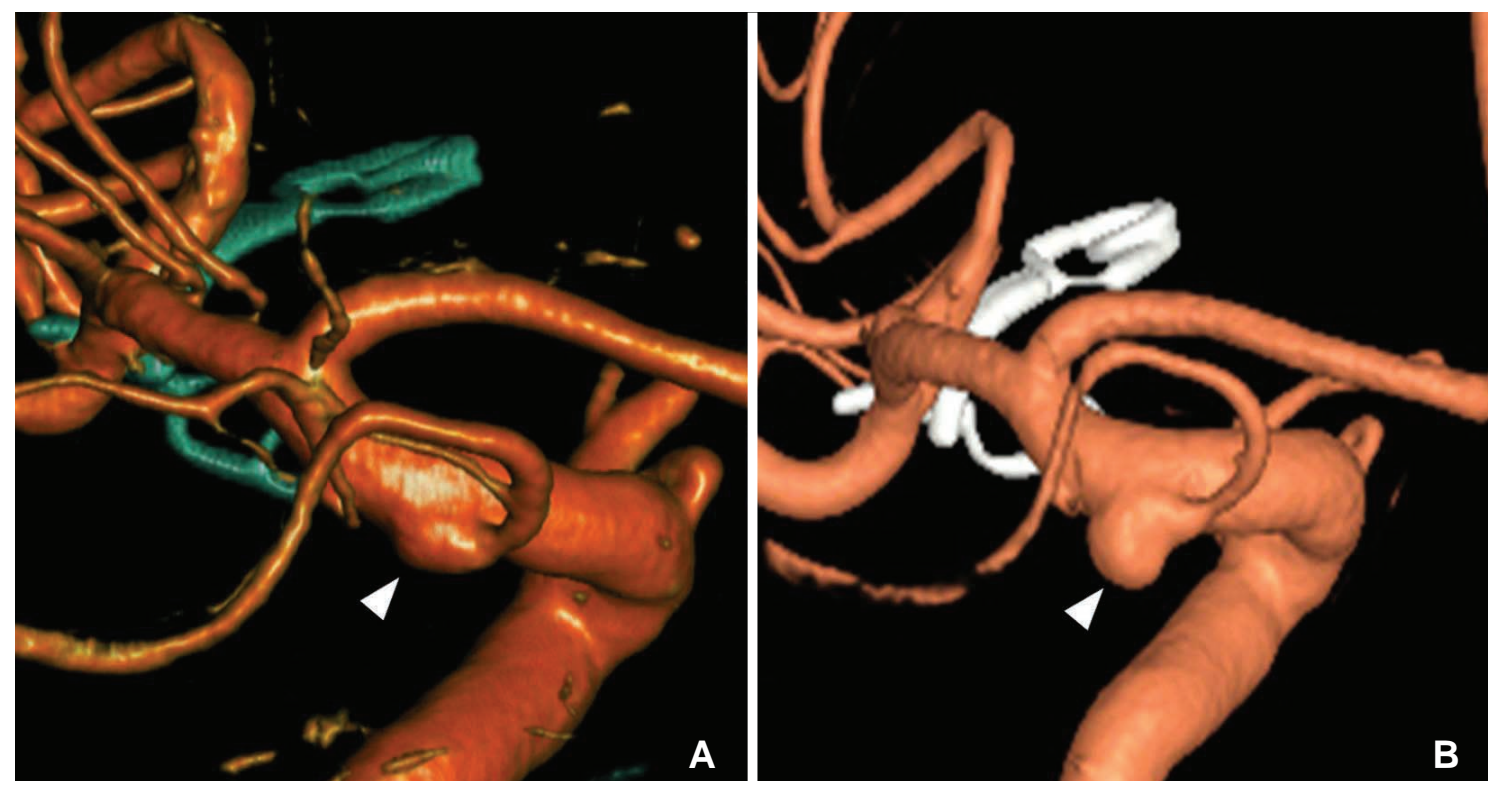

Fig. 3. A 55-year-old female (Case 3). (A) Initial angiogram showed a bleb (arrowhead) at junctional dilatation of the PcomA. (B) Followup angiogram obtained five years later revealed a de novo aneurysm (arrowhead) at the site of previous bleb.

junctional dilatation, which subsequently developed into a de novo saccular aneurysm during about 5-year duration. To the best of our knowledge, this observation of a tiny bleb at the junctional dilatation detected by $3 \mathrm{D}$ rotational angiography has not been described in the literature. Therefore, $3 \mathrm{D}$ rotational angiography is recommended to detect any bleb-like irregularities especially at the dominant side of bilateral junctional dilatations of the PcomA.

The junctional dilatations of cerebral arteries are most frequently observed at the origin of the PcomA as shown in our cases. It can be found in the other locations such as the anterior choroidal artery, the ophthalmic artery, the middle cerebral artery and the superior cerebellar artery. For the criteria of junctional dilatation which was proposed by Taveras and Wood in 1964 [2], it was defined as follows ; 1) diameter less than $3 \mathrm{~mm}$ and 2) the PcomA emerges from the apex of the enlargement.

Review of previous literature revealed six cases with a development of aneurysm from pre-aneurysmal junctional dilatations of the PcomA [7-13]. All six patients were female between 20 and 40 years of age. Five of them had a history of aneurysm involving other cerebral arteries. The junctional dilatations required 6 months to 9 years to develop into aneurysms. Some risk factors suggested for the evolution of de novo aneurysm from junctional dilatation were history of angiography-negative $\mathrm{SAH}$, familial occurrence of intracranial aneurysms and known disease with an increased propensity to aneurysm formation (e.g., adult polycystic kidney degeneration, Ehlers-Danlos disease, aortic coarctation) $[6,14]$. All 3 de novo aneurysms of our case report were found to be unruptured aneurysms on routine follow-up study as the most of previously reported cases were. However, some authors reported a rupture of de novo aneurysms developing from the junctional dilatation [15-17]. We do not know the exact time interval of the aneurysm development from junctional dilatation. The expected time period would be between one to five years in our cases.

In conclusion, our case showed that the junctional dilatation of PcomA can develop into a de novo aneurysm on long term follow-up. Notably, a tiny bleb noted on 3D rotational angiography can predispose to a subsequent de novo aneurysm at the junctional dilatation especially on the dominant side of PcomA.

\section{References}

1. Hassler O, Saltzman GF. Histologic changes in infundibular widening of the posterior communicating artery. A preliminary report. Acta Pathol Microbiol Scand 1959;46:305-312

2. Taveras JM, Wood EH: Diagnostic Neuroradiology. Baltimore : Williams and Wilkins, 1964, p 498

3. Endo S, Furuichi S, Takaba M, Hirashima Y, Nishijima M, Takaku A. Clinical study of enlarged infundibular dilation of the origin of the posterior communicating artery. J Neurosurg 1995;83:421-425

4. Epstein F, Ransohoff J, Budzilovich GN. The clinical significance of junctional dilatation of the posterior communicating artery. $J$ Neurosurg 1970;33:529-531

5. Itakura T, Ozaki F, Nakai E, Fujii T, Hayashi S, Komai N. Bilateral aneurysm formation developing from junctional dilata- 


\section{De Novo Aneurysm at Junctional Dilatation of PComA}

tion (infundibulum) of the posterior communicating arteries. Case report. J Neurosurg 1983;58:117-119

6. Fischer S, Hopf N, Henkes H. Evolution from an infundibulum of the posterior communicating artery to a saccular aneurysm. Clin Neuroradiol 2011;21:87-90

7. Drake CG. On the surgical treatment of ruptured intracranial aneurysms. Clin Neurosurg 1965;13:122-155

8. Stuntz JT, Ojemann GA, Alvord EC, Jr. Radiographic and histologic demonstration of an aneurysm developing on the infundibulum of the posterior communicating artery. Case report. J Neurosurg 1970;33:591-595

9. Trasi S, Vincent LM, Zingesser LH. Development of aneurysm from infundibulum of posterior communicating artery with documentation of prior hemorrhage. AJNR Am J Neuroradiol 1981;2:368-370

10. Waga S, Morikawa A. Aneurysm developing on the infundibular widening of the posterior communicating artery. Surg Neurol $1979 ; 11: 125-127$

11. Wollschlaeger G, Wollschlaeger PB, Lucas FV, Lopez VF. Experience and result with postmortem cerebral angiography performed as routine procedure of the autopsy. Am J Roentgenol Radium Ther Nucl Med 1967;101:68-87
12. Yoshimoto T, Suzuki J. Surgical treatment of an aneurysm on the funnel-shaped bulge of the posterior communicating artery. Case report. J Neurosurg 1974;41:377-379

13. Young B, Meacham WF, Allen JH. Documented enlargement and rupture of a small arterial sacculation. Case report. J Neurosurg 1971;34:814-817

14. Coupe NJ, Athwal RK, Marshman LA, Brydon HL. Subarachnoid hemorrhage emanating from a ruptured infundibulum: case report and literature review. Surg Neurol 2007;67:204-206

15. Marshman LA, Ward PJ, Walter PH, Dossetor RS. The progression of an infundibulum to aneurysm formation and rupture: case report and literature review. Neurosurgery 1998;43:1445-1448; discussion 1448-1449

16. Radulovic D, Nestorovic B, Rakic M, Janosevic V. Enlargement to a saccular aneurysm and subsequent rupture of infundibular widening of posterior communicating artery. Neurochirurgie 2006;52:525-528

17. Takahashi C, Fukuda O, Hori E, Kameda H, Endo S. A case of infundibular dilatation developed into an aneurysm and rupturing after the rupture of an aneurysm 10 years ago. No Shinkei Geka 2006;34:613-617 